\title{
Transplantation of human embryonic stem cell-derived oligodendrocyte progenitors into rat spinal cord injuries does not cause harm
}

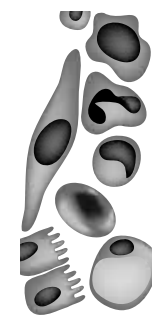

\section{FrankClatier', Manica M Siegenthaler ${ }^{1}$, Gabrid Nistor ${ }^{1} \&$ HansS Keirstead"}

${ }^{\dagger}$ Author for correspondence 1 University of California at Irvine, ReeveI Irvine Research Center, D epartments of Anatomy \& N eurobiologyl, College of M edicine, 2111 Gillespie N euroscience Research Facility, U niversity of California at Irvine, Irvine, CA, 92697-4292 USA

Tel.: +1 949824 6213; E-mail: hansk@uci.edu

Keywords demyelination, niche, oligodendrocyte progenitor, predifferentiation, rat, remyelination, transplantation

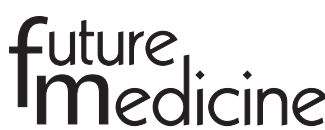

Demyelination contributes to loss of function following spinal cord injury. We have shown previously that transplantation of human embryonic stem cell-derived oligodendrocyte progenitors into adult rat $200 \mathrm{kD}$ contusive spinal cord injury sites enhances remyelination and promotes recovery of motor function. Previous studies using oligodendrocyte lineage cells have noted a correlation between the presence of demyelinating pathology and the survival and migration rate of the transplanted cells. The present study compared the survival and migration of human embryonic stem cell-derived oligodendrocyte progenitors injected 7 days after a 200 or 50 kD contusive spinal cord injury, as well as the locomotor outcome of transplantation. Our findings indicate that a $200 \mathrm{kD}$ spinal cord injury induces extensive demyelination, whereas a $50 \mathrm{kD}$ spinal cord injury induces no detectable demyelination. Cells transplanted into the $200 \mathrm{kD}$ injury group survived, migrated, and resulted in robust remyelination, replicating our previous studies. In contrast, cells transplanted into the $50 \mathrm{kD}$ injury group survived, exhibited limited migration, and failed to induce remyelination as demyelination in this injury group was absent. Animals that received a $50 \mathrm{kD}$ injury displayed only a transient decline in locomotor function as a result of the injury. Importantly, human embryonic stem cellderived oligodendrocyte progenitor transplants into the $50 \mathrm{kD}$ injury group did not cause a further decline in locomotion. Our studies highlight the importance of a demyelinating pathology as a prerequisite for the function of transplanted myelinogenic cells. In addition, our results indicate that transplantation of human embryonic stem cell-derived oligodendrocyte progenitor cells into the injured spinal cord is not associated with a decline in locomotor function.

Spinal cord injury ( $\mathrm{SCI}$ ) leads to the interruption of long tracts that carry information to and from the brain and distal regions of the spinal cord. Animal models of contusive $\mathrm{SCI}$ reveal that moderate lesions are incomplete and that the injury site is surrounded by spared tissue containing myelinated and demyelinated axons [1-4]. Following the initial trauma, spared tissue is subject to a secondary degenerative phenomenon that includes demyelination, in which the myelin sheath is lost. This problem, first reported in 1906 by H omes, has slowly gained interest and has been reported in different species including monkey [5], cat [6-8], guinea pig [9] and rat [10,11]. Demyelination is attributed to the initial mechanical insult and ensues within hours as a result of the death of oligodendrocytes by necrosis and apoptosis [12-16]. Electrophysiological and morphological studies have demonstrated that demyelination has detrimental functional effects, such as disruption of action potentials, rendering it a significant component of the $\mathrm{SCl}$ pathology $[7,17]$. Remyelination occurs following
$\mathrm{SCI}[18,19]$, but is a marginal event in comparison to demyelination, which we have previously shown to be a chronic and progressive phenomenon that continues well beyond a year following $\mathrm{SCl}$ in rat [11]. There is little information regarding demyelination and remyelination following $\mathrm{SCl}$ in humans, however, a growing body of morphological evidence suggests that the same phenomena occurs in humans [20-23].

0 ver the last two decades, several studies have demonstrated that myelination of host axons by transplanted oligodendrocyte-lineage cells is a pragmatic approach to recovering function. Transplant-mediated remyelination has been demonstrated in focal, gliotoxin-induced regions of demyelination in adult rat [24-26] and in neonatal myelin-deficient animals [27-31].

Efforts to translate this approach to humans are increasingly utilizing human embryonic stem cells (hESC s), which are capable of generating a seemingly unlimited cell supply for transplantation. $\mathrm{O}$ ur laboratory has developed a method to differentiate hESCs into 
oligodendroglial progenitor cells (OPCS) in high purity [32]. We have shown that transplantation of these cells into either the shiverer mouse model of dysmyelination or adult rat $200 \mathrm{kD}$ contusive SCIs results in the integration of transplanted cells, their differentiation into mature oligodendrocytes, the formation of compact myelin by transplanted cells and increased locomotor recovery [32,33]. Although transplantation of hESC-derived OPCs has been show to improve locomotor function, it is not known whether the transplant volume or the cells themselves may have deleterious effects that may have been masked by the severity of the $\mathrm{SCl}$, or the subsequent ben efit conferred by the transplant. Furthermore, it is not known whether demyelination is a pre-requisite to transplant-mediated recovery of locomotion.

In this study, we compared the survival and migration of hESC-derived OPCs injected 7 days after a $200 \mathrm{kD}$ or $50 \mathrm{kD}$ contusive $\mathrm{SCl}$, as well as the locomotor outcome of transplantation. O ur data indicate that a $50 \mathrm{kD} \mathrm{SCl}$ induces no demyelination, and that OPC transplantation in this injury group resulted in the survival and limited migration of cells, with no remyelination or alteration of locomotor outcome. These findings indicate that demyelination provides a pathological niche for the function of transplanted myelinogenic cells. Furthermore, our results indicate that transplantation of hESC-derived OPCs into the injured spinal cord is not associated with a decline in locomotor function.

\section{Materials \& methods \\ Cell culture}

$\mathrm{H}$ igh purity populations of OPC S were prepared from the $\mathrm{H} 7 \mathrm{hESC}$ line and weremaintained and amplified as previously described [32,34]. The $\mathrm{H} 7$ hESC line at passage 32 and the human fibroblast line at passage 48 were obtained from $G$ eron Corporation (CA, USA). Cells were expanded in hESC growth media [35] and differentiated as previously described [32]. Dissociated cells were placed for 2 days in 50\% hESC growth media, and $50 \%$ glial restriction media (GRM). GRM consisted of DMEM:F12, B27 supplement (G ibco-Invitrogen, CA, USA), $25 \mu \mathrm{g} / \mathrm{ml}$ insulin, $6.3 \mathrm{ng} / \mathrm{ml}$ progesterone, $10 \mu \mathrm{g} / \mathrm{ml}$ putrescin, $50 \mathrm{ng} / \mathrm{ml}$ sodium selenite, $50 \mu \mathrm{g} / \mathrm{ml}$ holotransferin, $40 \mathrm{ng} / \mathrm{ml}$ tri-iodo-thyroidin, $4 \mathrm{ng} / \mathrm{ml}$ basic fibroblast growth factor (bFGF) and $10 \mathrm{ng} / \mathrm{ml}$ epidermal growth factor (EGF; Sigma-Aldrich, St. Louis, M O, USA). The transition media was supplemented for 1 day with $4 \mathrm{ng} / \mathrm{ml} \mathrm{bFGF}$ and $20 \mathrm{ng} / \mathrm{ml} \mathrm{EGF}$ (Sigma-Aldrich). Cells were then exposed to transition media supplemented with $2 \mathrm{ng} / \mathrm{ml} \mathrm{bFGF}, 20 \mathrm{ng} / \mathrm{ml}$ EGF (Sigma-Aldrich), and $10 \mu \mathrm{M} / \mathrm{ml}$ all-trans-retinoic acid (RA; Sigma-Aldrich) in dimethyl sulphoxide (D M SO ; Sigma-Aldrich) for 1 day.

This media was then replaced with 100\% GRM supplemented with $20 \mathrm{ng} / \mathrm{ml}$ EGF (Sigma-Aldrich) and $10 \mu \mathrm{M} / \mathrm{ml}$ all-trans-RA in D M SO for a further 7 days. RA was then omitted from media for the duration of the differentiation protocol. Cells were exposed to GRM supplemented with $20 \mathrm{ng} / \mathrm{ml} \mathrm{EGF}$ for 25 days. Cultures were then exposed to Trypsin-ethylenediaminetetraacetic acid (EDTA; Gibco-Invitrogen, CA, USA) for 2-5 min, plated on 1:30 $M$ atrigel substrate, and cultured for 1 week in GRM supplemented with $20 \mathrm{ng} / \mathrm{ml} \mathrm{EGF}$. Thus, the differentiation protocol took 42 days.

\section{Immunocytochemical staining}

Cultures were fixed 1 week later by exposure to $4 \%$ paraformaldehyde (Fisher Scientific, Pittsburgh, PA, USA) in phosphate buffer (PB) for 10 min. Nuclear staining was conducted by exposing cultures to $M$ ayer's hematoxylin for 10 min and blue staining in ammonia water for 10 min. I mmunocytochemical staining was performed using standard protocols. Imaging slides were blocked with $20 \%$ serum for 30 min at room temperature. Primary antiserum (rabbit anti-N G-2, 1:100; rabbit anti-SOX10, 1:200 [Chemicon, Temecula, CA, USA]; mouse antiTuj1, 1:200, rabbit anti-Pax6, 1:100 [not shown; CRP Incorporation, D enver, PA, USA]; rabbit anti-cow GFAP, 1:500 [DAKO, Denmark]; mouse anti-SSEA4 supernatant, 1:5 [a kind gift from Geron Corporation]; rabbit anti-PD GFR$\alpha, 1: 200$ [Santa Cruz Biotechnology Inc., Santa Cruz, CA, USA]) were diluted in $4 \%$ serum and applied to imaging chambers overnight at $4^{\circ} \mathrm{C}$. Imaging chambers were rinsed three times with phosphate buffered saline (PBS), incubated for $30 \mathrm{~min}$ in $20 \%$ serum, and biotinylated antisera (rabbit anti-goat, goat anti-mouse or goat antirabbit biotinylated immunoglobulin G (IgG) $\mathrm{H}+\mathrm{L}, 1: 200$ [Vector Laboratories, CA, USA]) was applied and incubated for $1 \mathrm{~h}$ at room temperature. For immuno-fluorescence, goat antirabbit or goat anti-mouse secondary antibodies (Alexa Fluor 488 or 594, Molecular Probes, Eugene, OR, USA) were used at a dilution of $1: 200$ in $10 \%$ N GS in PBS. Cell quantification was conducted using an Olympus AX-80 light 
microscope. The percentage of immunopositive cells was determined by dividing the total number of immunopositive cells by the total number of hematoxylin positive cells in each imaging chamber, and averaging the results from three imaging chambers per marker.

Spinal cord injury

Female Sprague Dawley adult rats (200-220 g, 6-8 weeks old) were anesthetized with an intraperitoneal injection of $7.5 \mathrm{mg} / \mathrm{kg}$ Xylazine (Phoenix Pharmaceutical Inc., MO, USA) and $60 \mathrm{mg} / \mathrm{kg}$ Ketamine (Phoenix Pharmaceutical Inc.). The dorsal area between the neck and hindlimbs, and extending approximately $2 \mathrm{~cm}$ bilaterally from the spine, was shaved and disinfected with serial provodone and $70 \%$ ethanol scrubs. A midline incision exposed the spinal column at the level of T 8-T11 and the paravertebral muscles were dissected bilaterally to visualize the transverse apophyses. Laminectomy was performed at the 10th thoracic vertebra. The exposed vertebral column was stabilized by clamping the rostral T 9 and caudal T 11 vertebral bodies with Adson delicate stabilizing forceps (M iltex no. 6-120; M iltex Instruments $\mathrm{C}_{0}$., NY, USA). Contusion injury was induced using the Infinite Horizon Impactor $^{\mathrm{TM}}$ (Precision Systems and Instrumentation, LLC) with a force of $50 \mathrm{kD}(\mathrm{n}=19)$ or $200 \mathrm{kD}$ $(n=14)$ defined by the level of force applied to the exposed spinal cord. The deep and superficial muscle layers were sutured and the skin was closed with stainless steel wound clips. Immediately following surgery, animals were administered subcutaneous saline and prophylactic Baytril ${ }^{\mathrm{TM}}$ (Bayer, $\mathrm{KS}$, USA; $2.5 \mathrm{mg} / \mathrm{kg} /$ day, subcutaneously) and maintained on an isothermic pad until alert and mobile. Animals receive manual bladder expression twice daily and were inspected for weight loss, dehydration, discomfort and autophagia, with appropriate veterinary care as needed.

Behavioral testing

Before injury, each animal was acclimated and scored using the Basso, Beattie, Bresnahan Locomotor Rating Scale (BBB) [36]. Animals were scored onceper week for the duration of thestudy. BBB scores were analyzed by repeated measures analysis of variance with Tukey's multiple comparison test at each time point.

Cell transplantation

Animals received cyclosporin A (10 mg/kg/day, subcutaneously; Bedford Laboratories, $\mathrm{OH}$, USA) beginning 1 day prior to transplantation and every day thereafter until the end of the study. Transplantation surgeries occurred 7 days following contusion surgery. Immediately prior to transplant, the cell transplant population was assayed for viability by assessing trypan blue exclusion and only populations with over 95\% viability were transplanted. Animals were anesthetized as above and the laminectomy site reexposed. After immobilization of the spinal process rostral to the contusion site, a $10 \mu \mathrm{l}$ $\mathrm{H}$ amilton syringe ( $\mathrm{H}$ amilton, $\mathrm{N} \mathrm{V}, \mathrm{USA}$ ) with a silicon-coated pulled glass tip was lowered into the spinal cord using a stereotactic manipulator arm. Cell suspensions were injected along the midline of the spinal cord into one site at the cranial end of the laminectomy and one site at the caudal end of the laminectomy, in a total volume of $15 \mu \mathrm{l}(1,500,000$ cells) ( $n=10$ for $50 \mathrm{kD}$ injuries; $n=7$ for $200 \mathrm{kD}$ injuries). The needle was removed after 5 minutes. Control animals ( $n=9$ for $50 \mathrm{kD}$ injuries; $n=7$ for 200 $\mathrm{kD}$ injuries) received human fibroblasts (a gift from Geron Corporation) at similar concentrations. In order to determine how far cells are distributed as a result of the implantation procedure itself, some animals $(n=4)$ received $200 \mathrm{kD}$ injuries followed by transplantation of a total volume of $15 \mu \mathrm{l}(1,500,000$ cells $)$ of hESC-derived OPCs, and were killed the following day.

Histology

Animals were terminally anesthetized 7 weeks after cell transplantation and transcardially perfused with $50 \mathrm{ml}$ of $0.1 \mathrm{M}$ PBS containing $28 \mathrm{IU} / \mathrm{ml}$ heparin (Acros, NY, U SA) followed by $250 \mathrm{ml}$ of $4 \%$ paraformaldehyde (Fisher Scientific, PA, USA) in 0.1 M PB pH 7.4. Spinal cord regions extending $1 \mathrm{~cm}$ above and $1 \mathrm{~cm}$ below the injection/injury site were post fixed overnight. Spinal cords were cut into $1 \mathrm{~mm}$ transverse blocks and processed so as to preserve the cranio-caudal sequence and orientation.

Tissue for cryostat processing was transferred to $27 \%$ sucrose (Fisher Scientific, N H , USA) for $24 \mathrm{~h}$ prior to transverse sectioning at $20 \mu \mathrm{m}$, and was then mounted on gelatin-coated slides (Fisher Scientific). Mouse anti-human nuclei antibodies (Chemicon) were used at a dilution of $1: 200$ in $0.5 \%$ normal goat serum (N GS) in PBS (Chemicon International Inc., CA, USA). Primary antibodies were incubated overnight at $4^{\circ} \mathrm{C}$. Goat anti-rabbit secondary antibodies (Alexa Fluor 594) were used at a dilution of $1: 200$ in $10 \%$ NGS in PBS. Following $2 \mathrm{~h}$ of 
incubation, all sections were washed in PBS. Standard immunohistochemical controls were included in each run. Sections were viewed and digitally photographed using an O lympus AX -80 microscope using O LYM PUS M icroSuite B3SV software (O lympus America Inc., NY, USA).

Resin sections were used for the examination of remyelinated and demyelinated axons, and the gross pathology of the transplant environment. For resin processing, odd-numbered spinal cord blocks were post fixed for $24 \mathrm{~h}$ in $4 \%$ glutaraldehyde (Fisher Scientific) then exposed to $1 \%$ osmium tetroxide $\left(\mathrm{O} \mathrm{SO}_{4}\right.$ ) (Electron M icroscopy Sciences, Fort Washington, PA, USA), dehydrated in ascending alcohols, and embedded in Spurr resin (Electron M icroscopy Sciences, PA, USA) according to standard protocols. Transverse semi-thin $(1 \mu \mathrm{m})$ sections were cut from the rostral face, stained with alkaline toluidine blue, cover slipped and examined by light microscopy on an Olympus AX-80 microscope using O LYM PU S M icroSuite B3SV software.

Results

Myelin histopathology

Analysis of toluidine blue-stained sections revealed no demyelination pathology following $50 \mathrm{kD}$ injuries (Figure 1A-E), whereas demyelination was a prominent pathological feature following $200 \mathrm{kD}$ injuries (Figre $\mathbf{1 F}$-J). Low magnification (40x) imaging revealed minimal pathology following a $50 \mathrm{kD}$ injury, both at the injury epicenter (Figure 1A) and away from the injury epicenter (Figure1B). H igher magnification (200x) imaging of the dorsal columns of $50 \mathrm{kD}$ injuries also revealed minimal pathology with numerous healthy myelinated axons (Figre 1C). $H$ igh magnification (1000x) imaging revealed that structural integrity within the dorsal column was maintained with no detectable loss of myelin sheaths (Figure $\mathbf{I D}$ ). Very high magnification (2000x) imaging confirmed no detectable loss of myelin sheaths (Figre 1E). In contrast, low magnification (40X) imaging of $200 \mathrm{kD}$ injuries revealed widespread pathology with a clear region of demyelination in the dorsal column as well as in the lateral and ventral white matter, both at the injury epicenter (Figure 1F) and away from the injury epicenter (Figure 1G). H igher magnification (200x) imaging of $200 \mathrm{kD}$ injuries revealed hypercellularity, swelling, and demyelination of axons within the dorsal column (Figure 1H). High magnification (1000x) imaging revealed extensive demyelination of axons as evidenced by the lack of dark staining myelin sheaths (Figure $\mathbf{1})$ ). Very high magnification imaging confirmed extensive demyelination of axons (Figure 1 ). The presence of axons without their myelin sheaths indicates that some axons survive injury, despite loss of their myelin sheath. $M$ acrophage and immune cell infiltration were consistent features of $200 \mathrm{kD}$ injuries.

\section{Generation of OPCs from hESCS}

The differentiation protocol generated a high percentage of OPCs, confirming our previous findings $[32,33]$. Cultures consisted of high purity yellow spheres by 10 days of the differentiation protocol (Figre2A). At the end of the 42-day differentiation protocol, cells had a bipolar morphology (Figure 2B) characteristic of immature oligodendroglial cells and a typical antigenic profile, with a high percentage of $\mathrm{NG}^{+}$cells (>80\%; Figure 2C), SO $\times 10^{+}$cells $(>45 \%$; Figre2D), and PDGFR $\alpha^{+}$cells ( $>85 \%$; Figre2E). Cells that did not label with oligodendroglial markers were primarily GFAP+ or Tuj $1^{+}$ (Figre 2F). This panel of markers demonstrates oligodendroglial lineage commitment. No SSEA4 ${ }^{+}$cells could be detected at this point in the differentiation protocol indicating that undifferentiated stem cells could not be detected in the transplant population.

Survival \& migration of transplanted OPCs

Analysis of transplanted animals 2 months after implantation indicated that $\mathrm{hESC}$-derived OPCs survived and migrated when transplanted into $200 \mathrm{kD}$ injuries, confirming our previous findings [33]. Anti-human nuclear staining revealed clusters (arrow head) of antihuman nuclei-positive cells in all transplanted animals (Figre3A). In all animals in the $200 \mathrm{kD}$ injury group, anti-human nuclei-positive cells (arrows) spread from the site of implantation into the adjacent white matter. The greatest density of anti-human nuclei-positive cells was detected at the site of implantation and the number rapidly decreased cranially and caudally; cells were detected up to $6 \mathrm{~mm}$ cranial or caudal to the implantation site in the $200 \mathrm{kD}$ injury group. In contrast, although anti-human nuclei-positive cells were detected in all animals in the $50 \mathrm{kD}$ injury group, they failed to migrate from the site of transplantation (Figure3B). Transplanted cells consistently remained clustered at the site of implantation with very limited spread into the surrounding tissue (Figure3B), or cranial or caudal to the site of implantation (not shown). 
Figure 1. Comparative analysis of toluidine blue-stained sections from 50 kD and 200 kD spinal cord contusion injuries.
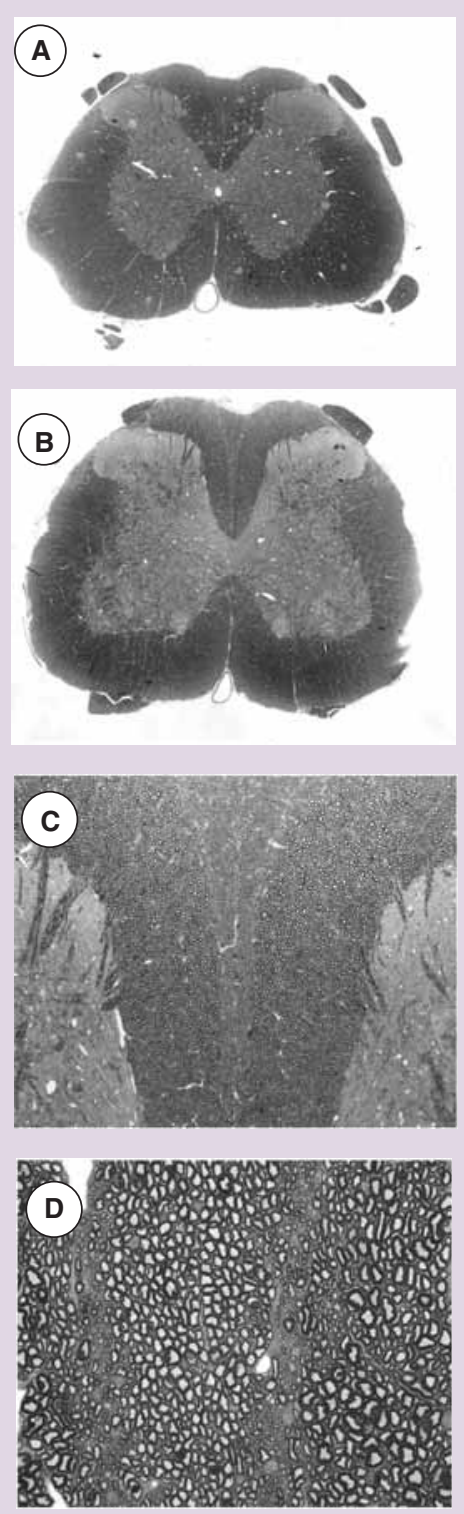
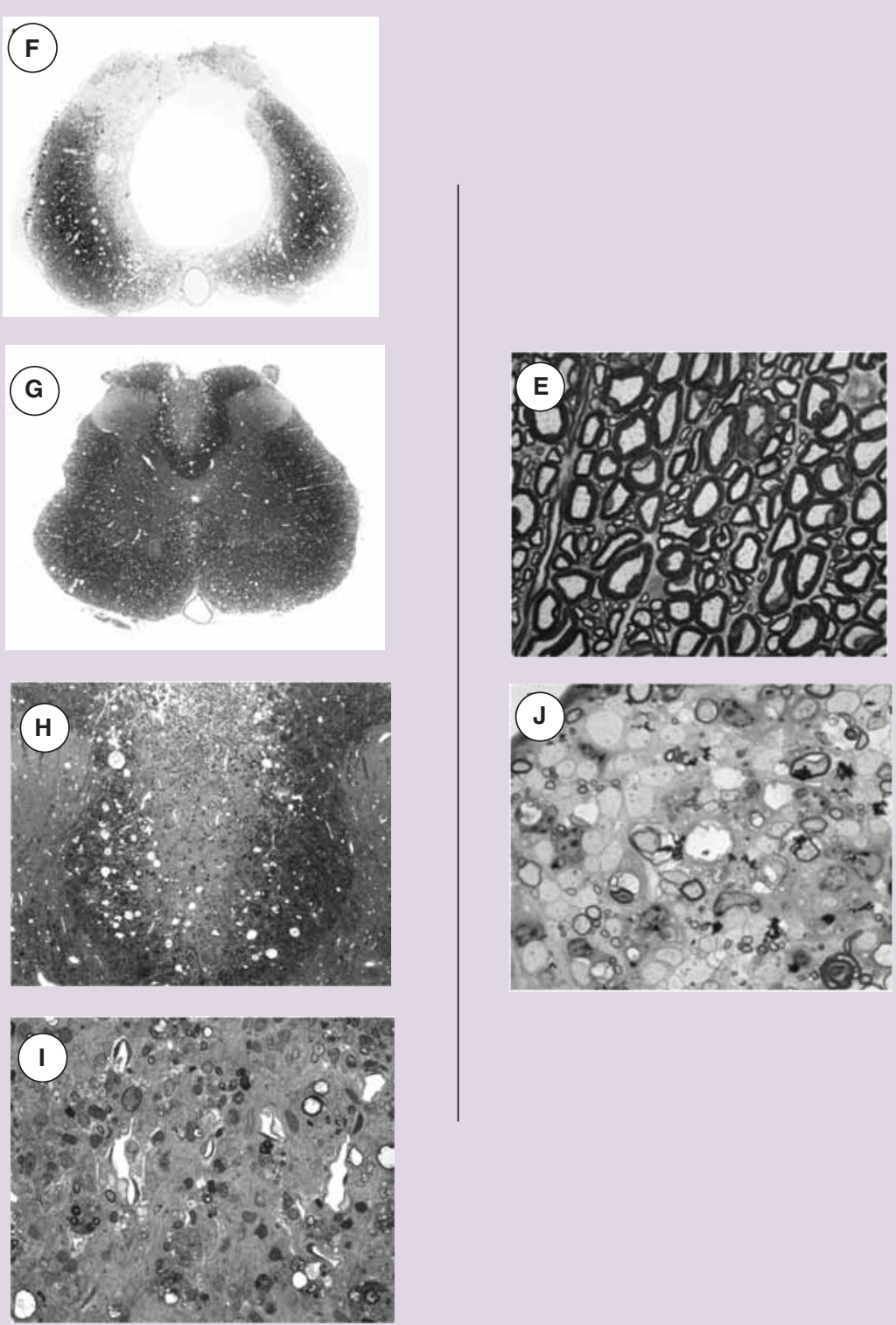

Histopathology following a $50 \mathrm{kD} \mathrm{SCl}$ at $40 \times(\mathbf{A}), 40 \times(\mathbf{B}), 200 \times(\mathbf{C}), 1000 \times$ (D), and $2000 \times$ (E) magnification. (A) Low magnification imaging reveals minimal pathology, with minor swelling of the central canal at the lesion epicenter. (B) Low magnification imaging reveals minimal pathology $2 \mathrm{~mm}$ caudal to the injury epicenter. (C) Higher magnification imaging of the dorsal column also reveals minimal pathology $2 \mathrm{~mm}$ caudal to the injury epicenter. (D) High magnification imaging reveals that structural integrity was maintained with no detectable loss of myelin sheaths $2 \mathrm{~mm}$ caudal to the injury epicenter. (E) Very high magnification imaging reveals no detectable loss of myelin sheaths $2 \mathrm{~mm}$ caudal to the injury epicenter. Histopathology following a $200 \mathrm{kD}$ contusive $\mathrm{SCl}$ at $40 \times(\mathbf{F}), 40 \times(\mathbf{G})$, $200 \times(\mathbf{H}), 1000 \times(\mathbf{I})$, and $2000 \times(\mathbf{J})$ magnification. (F) Low magnification imaging reveals widespread pathology with vast tissue necrosis and cavity formation at the lesion epicenter. (G) Low magnification imaging reveals widespread pathology with a clear region of demyelination in the dorsal column, $2 \mathrm{~mm}$ caudal to the injury epicenter. (H) Higher magnification imaging reveals hypercellularity, swelling, and a loss of myelin within the dorsal column, $2 \mathrm{~mm}$ caudal to the injury epicenter. (I) High magnification imaging reveals extensive demyelination of axons as evidenced by the lack of dark stained myelin sheaths, $2 \mathrm{~mm}$ caudal to the injury epicenter. (J) Very high magnification imaging reveals extensive demyelination $2 \mathrm{~mm}$ caudal to the injury epicenter. 


\section{Figure 2. Characterization of human embryonic stem cell-derived oligodendrioglial progenitor cells.}
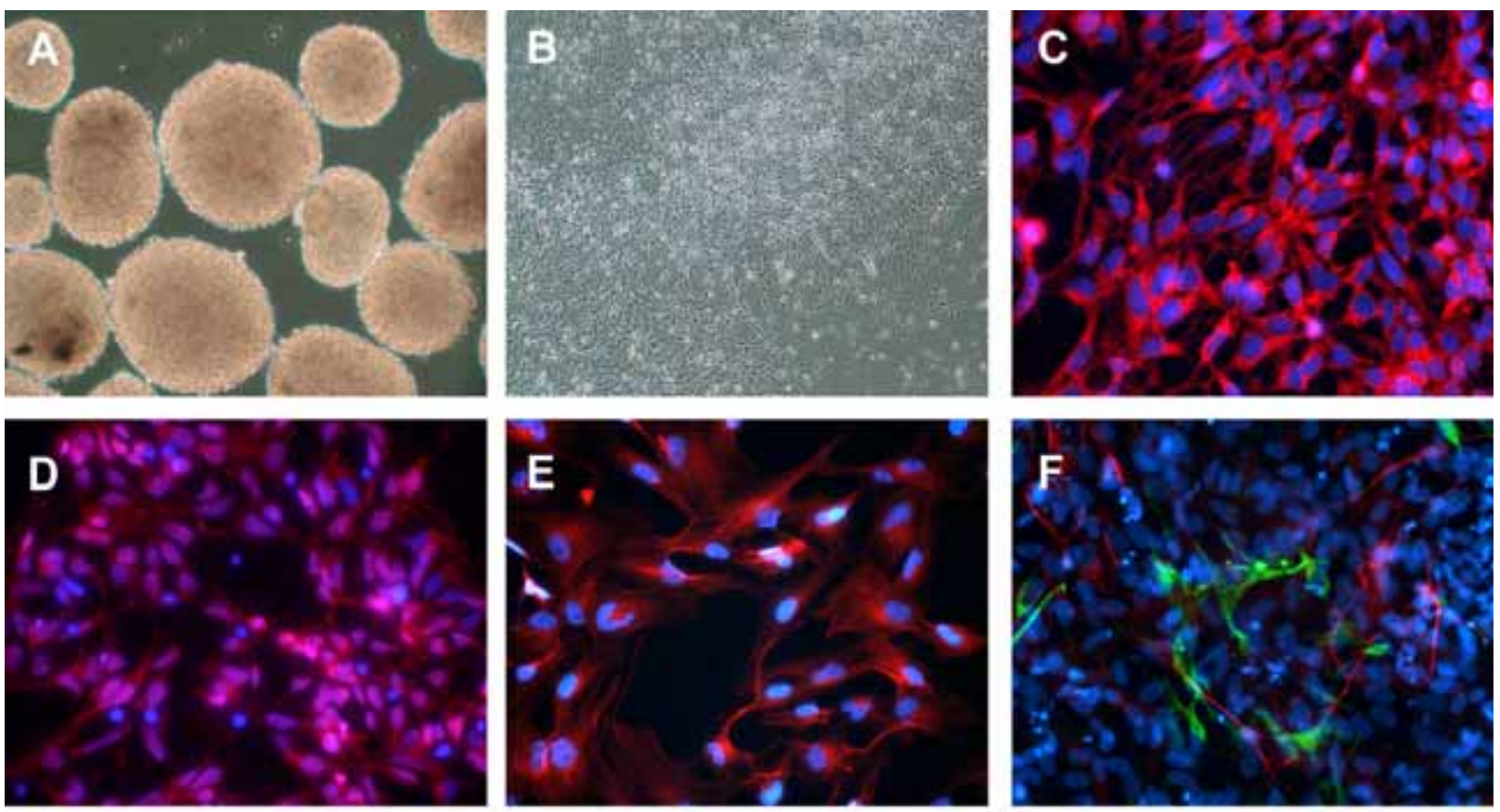

(A) Yellow spheres appeared within 5 days of exposure to retinoic acid (RA) and grew rapidly in the presence of glial restriction media (GRM), evidenced by an increase in their size and proportion relative to other culture components. (B) Cells migrated from plated neurospheres, allowing visualization of the bipolar cellular morphology, which is typical of early oligodendroglial lineage cells. (C) A high percentage of cells expressed NG2 (red), a marker for oligodendrioglial progenitor cells (OPCs). (D) A high percentage of cells expressed SOX10 (red), a marker for OPCS. (E) A high percentage of cells expressed platelet-derived growth factor receptor (PDGFR) $\alpha$ (red), a marker for OPCs. (F) The few cells that did not label with oligodendroglial markers were primarily GFAP (green) positive or Tuj1 (red) positive. Hoechst nuclear staining is shown in blue in C, D, E, and F. $4 \times(A), 40 \times(B)$, and $400 \times(C), 400 \times(D), 400 \times(E)$, and $400 \times(F)$.

Analysis of transplanted animals 1 day after transplantation revealed transplanted cells only within the lesion epicenter. The lack of human cells in tissue cranial or caudal to the implantation site in these animals indicates that the implantation procedure itself did not propel cells throughout the spinal cord.

\section{Locomotor outcome following \\ OPC transplantation}

Animals in the $50 \mathrm{kD}$ injury group demonstrated a minor and transient loss of locomotor function, with a low point of 18-19 (range: 14-21) on the BBB score scale at day 1 post injury (Figre4). Animals returned to a normal behavioral score of 21 around 2 weeks following transplantation and maintained normal behavioral scores for the remainder of the 2 months of behavioral assessment. Transplantation of either human fibroblasts or hESC-derived OPCS 7 days post-injury did not decrease locomotor outcome resulting from the $50 \mathrm{kD}$ injury. These observations suggest that cell transplantation does not cause substantial damage that can be detected with this assessment of locomotor function.

\section{Remyelination following}

OPC transplantation

Comparative analysis of toluidine bluestained sections from the $50 \mathrm{kD}$ injury group and the $200 \mathrm{kD}$ injury group after transplantation of hESC - derived O PCs are depicted in Figre5. Low magnification (40x) imaging of transplanted animals with a $50 \mathrm{kD}$ injury revealed minimal pathology (Figure 5A). Higher magnification (200x) imaging of the dorsal column of transplanted animals with a $50 \mathrm{kD}$ injury also revealed minimal pathology (Figre 5B). H igh magnification $(1000 x)$ imaging of these regions revealed that axonal and myelin structural integrity was maintained; no demyelination or remyelination was detected (Figre 5C). Very high magnification imaging (2000X) confirmed no detectable loss of myelin sheaths, and no remyelination (Figre 5D). 
Figure 3. Immunostaining for anti-human nuclei showing the distribution of anti-human-positive cells at the site of implantation 2 months following a $200 \mathrm{kD}$ (A) and $50 \mathrm{kD}$ (B) contusive spinal cord injury.
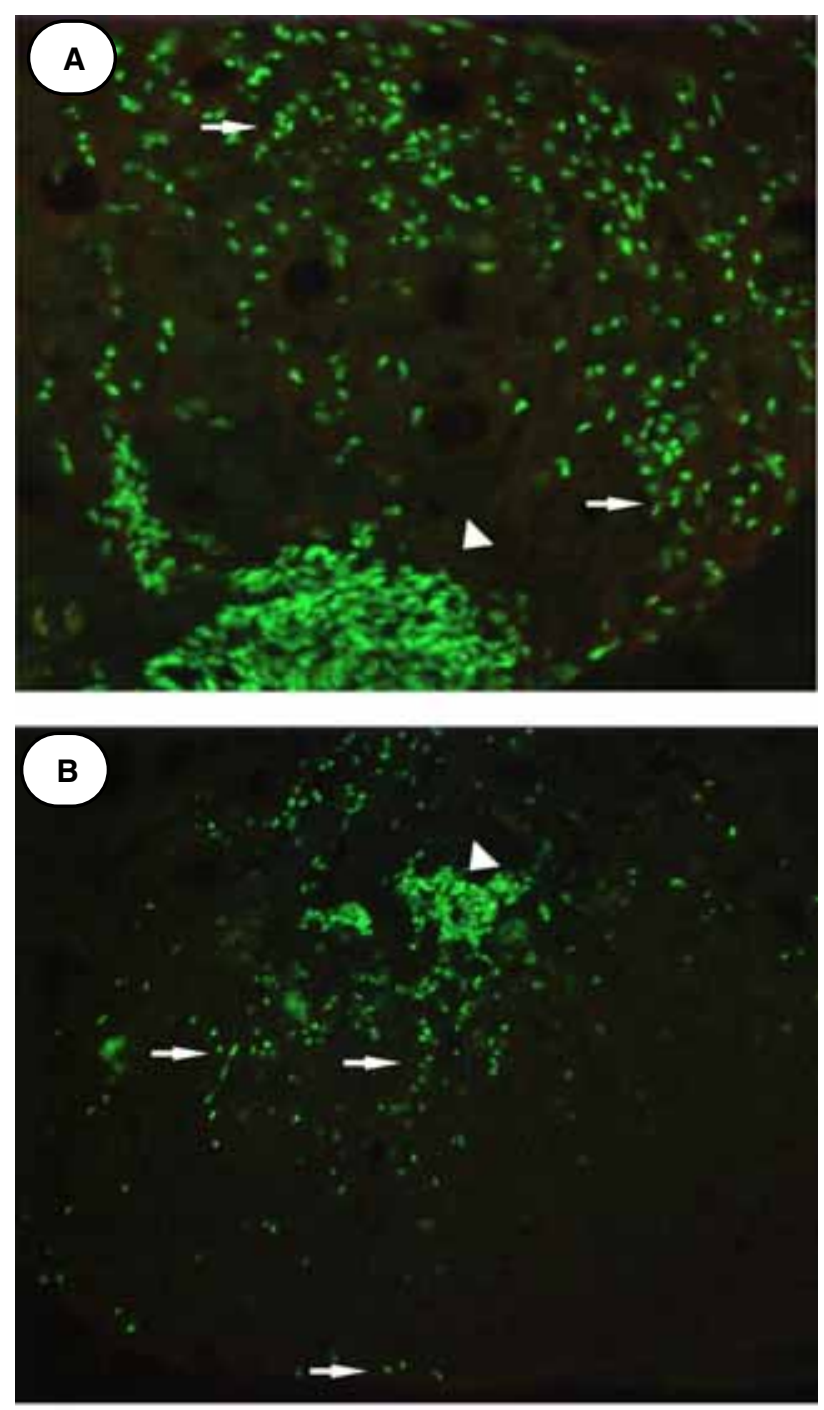

Whereas a cluster (arrow head) of anti-human-positive cells and spread (arrows) of anti-human-positive cells were detected in all rats in the $200 \mathrm{kD}$ injury group, anti-human-positive cells were restricted to the site of implantation in all animals within the $50 \mathrm{kD}$ injury group. $200 \times$ (A), $400 \times$ (B). of transplanted animals with a $200 \mathrm{kD}$ injury revealed regions of pathology in the dorsal column, suggestive of remyelination (Figure 5F). High magnification (1000x) imaging of these regions revealed extensive oligodendrocyte remyelination, as evidenced by the thin myelin sheaths relative to the axon diameter (Figre5G). Very high magnification (2000X) imaging confirmed extensive remyelination (Figre5H). These data confirm previous findings using a similar injury and transplant regime [33]. O ur previous studies have indicated that remyelination following hESC-derived OPC transplantation is conducted by the transplanted cells [33].

Remyelination was exceedingly rare in human fibroblast-transplanted animals with a $200 \mathrm{kD}$ injury, and absent in animals with a $50 \mathrm{kD}$ injury.

\section{Discussion}

O ur laboratory has recently shown that transplantation of pre-differentiated hESC-derived OPCs into moderate $(200 \mathrm{kD})$ contusion injuries in adult rats results in integration of transplanted cells, their differentiation into mature oligodendrocytes, the formation of compact myelin by transplanted cells, and increased locomotor recovery $[32,33]$. In this study, we compared the survival and migration of hESCderived O PCs injected 7 days after a $200 \mathrm{kD}$ or $50 \mathrm{kD}$ contusive $\mathrm{SCl}$, as well as the locomotor outcome of transplantation.

This study is the first to examine demyelination following a $50 \mathrm{kD} \mathrm{SCl}$, and the fate of transplanted myelinogenic cells in this model. Our analyses revealed minimal pathology in the $50 \mathrm{kD}$ contusion model with no detectable demyelination. Following transplantation of $\mathrm{hESC}$-derived $O P C s$ into the $50 \mathrm{kD}$ injury group, major histopathologic changes were not detected. Survival of transplanted cells was evident in all transplanted animals, although it is likely that the number of surviving cells was far less than the number of cells transplanted. Oligodendrocyte lineage death has been described in developing animals as a means to adjust the number of myelinating cells to the available axons [37,38]. In the developing rat optic nerve, approximately half of the oligodendrocyte progenitors generated differentiate into myelin-forming oligodendrocytes, while the majority of the remainder undergo apoptotic cell death $[37,39,40]$. In the developing rat cerebral cortex, the same phe nomenon is observed, with a loss of approximately $20 \%$ of premyelinating oligodendrocytes between postnatal days $7-11$ and $37 \%$ by day 28 [4]]. Interestingly, the oligodendrocytes that die are those 


\section{Figure 4. Behavioral assessment following a 50 kD contusive injury using the BBB locomotor rating scale.}

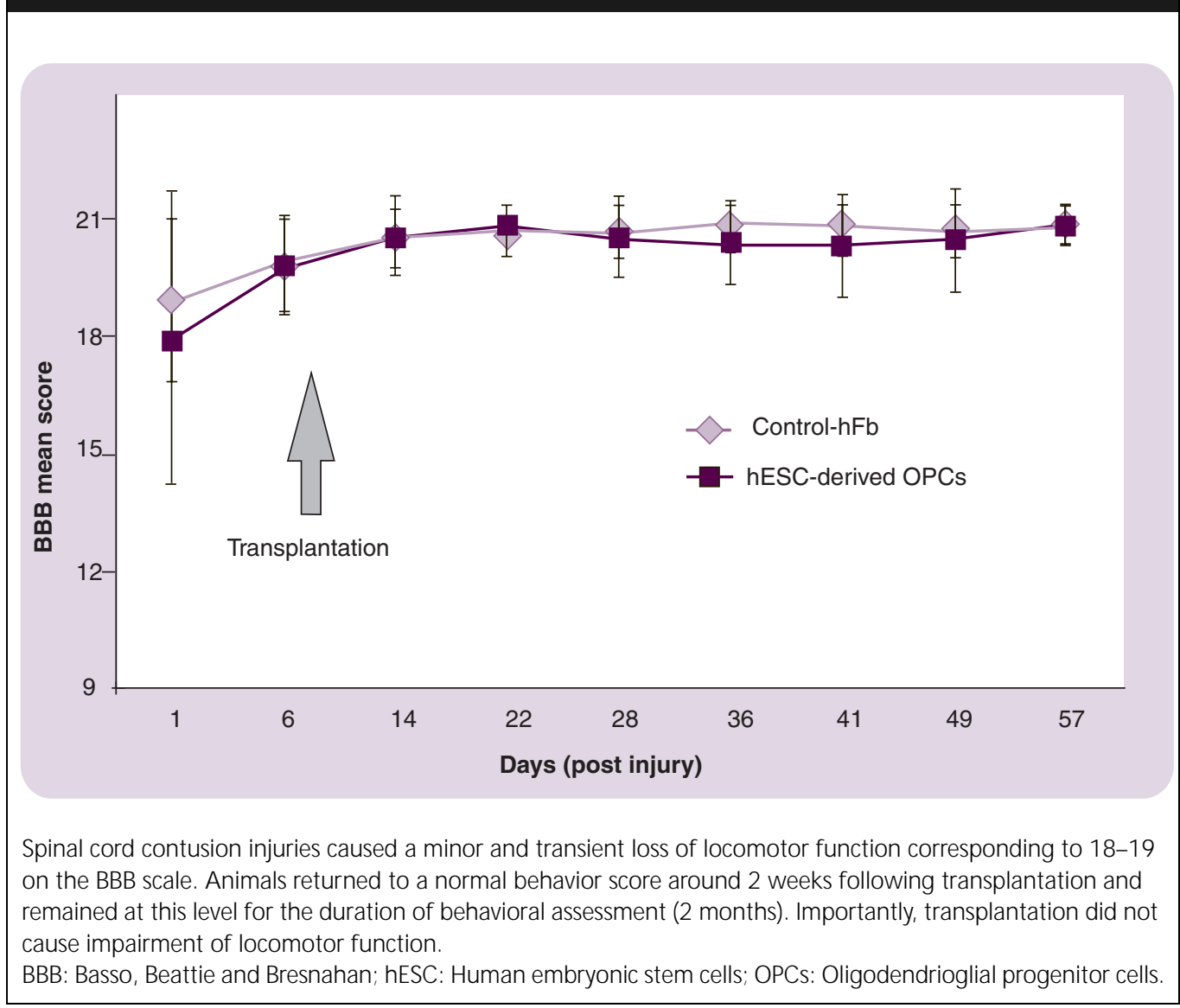

that fail to contact axons, suggesting that axons affect oligodendrocyte survival. A striking decrease in the total number of oligodendrocytes and their precursors is observed following transection of neonatal rat optic nerves, whereas animals in which the number of axons is increased by genetic manipulation show a proportional increase in oligodendrocyte numbers $[37,42,43]$. These studies and others $[44,45]$ support the hypothesis that axonal contact is necessary for oligodendrocytes to receive survival signals.

Growth factors associated with the extra-axonal compartment of the CN S also affect survival and myelinogenic capacity of oligodendrocytes and their progenitors. Numerous oligodendrocyte growth factors have been identified, including insulin growth factor (IGF)-1 [46-48], neurotrophin-3 [49-52], neurogulins [53], platelet-derived growth factor (PDGF) $[37,48]$ and ciliary-neurotrophic factor (CNTF) [54-56]. The naturally occurring loss of oligodendrocytes during development of the rat optic nerve can be prevented by delivery of exogenous PDGF and CNTF $[37,48]$. Several experimental models of demyelination that support transplant-mediated remyelination express growth factors with known effects on the oligodendroglial lineage. Thus, IGF-1 levels are elevated in cuprizone-induced demyelination [57], and PDGF is upregulated in the lysolecithin model of demyelination $[58,59]$. It is likely that such factors are either not present or are insufficiently expressed following a $50 \mathrm{kD}$ injury, but are expressed following the more severe $200 \mathrm{kD}$ injury that supports transplant-mediated remyelination.

A growing body of evidence supports the concept that inflammatory responses within the CN S promote the survival, proliferation, migration, and differentiation of transplanted OPCs. The survival and migratory capacity of transplanted OPCs is far greater in the rat experimental autoimmune encephalomyelitis model than in normal tissue [60]. These authors have speculated that cytokines expressed in active demyelinating foci might have a positive effect on the survival and migration of OPCS. Recently, Foote and Blakemore have shown that inflammation is conducive to OPC proliferation and differentiation into myelinating oligodendrocytes [63]. In addition, their studies 
Figure 5. Comparative analysis of toluidine blue-stained sections from $\mathbf{5 0}$ kD and $200 \mathrm{kD}$ spinal cord contusion injuries after transplantation of hESC-derived OPCs.
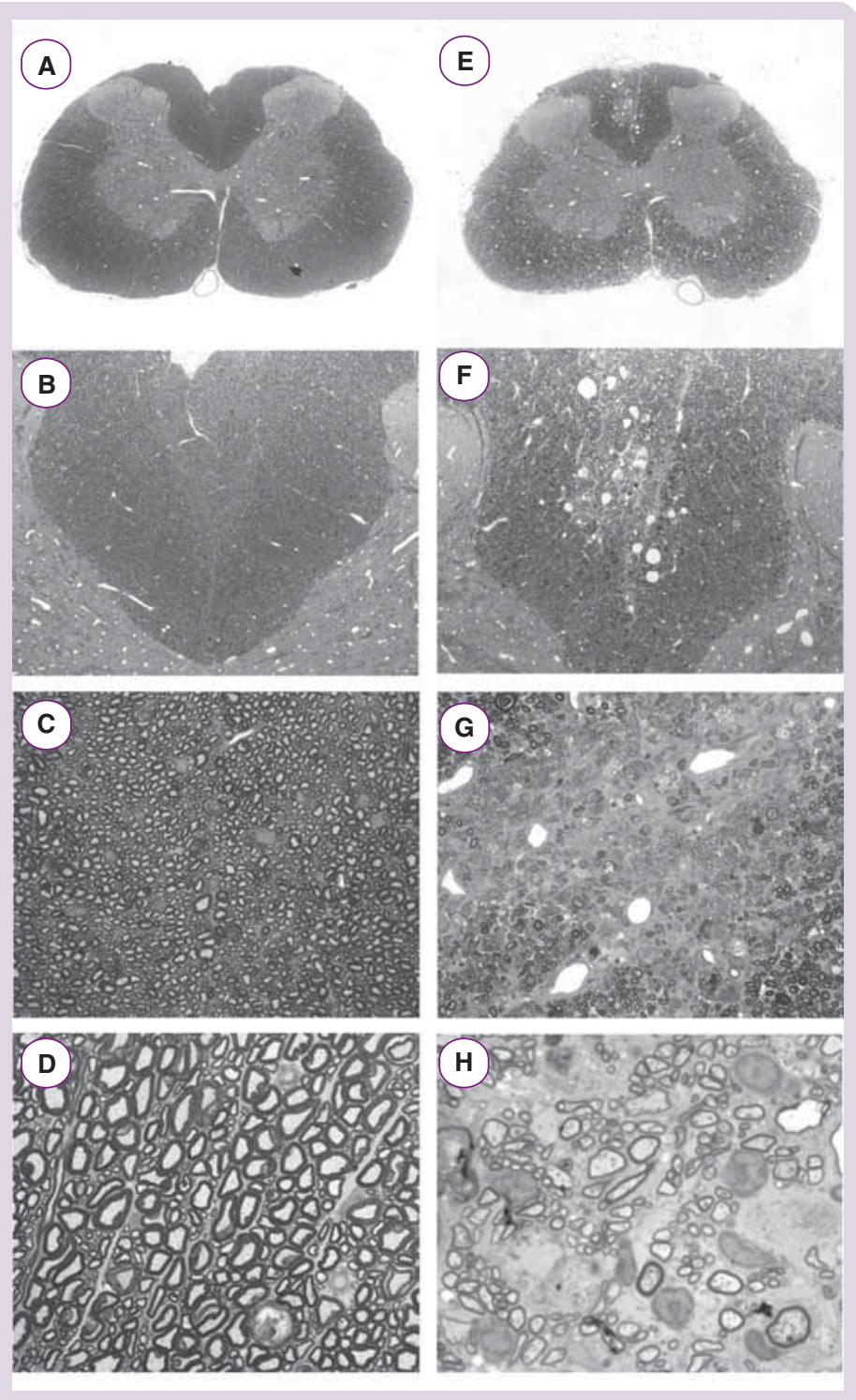

These images are from tissue sections $2 \mathrm{~mm}$ caudal to the injury epicenter. Histopathology following transplantation of human embryonic stem cell (hESC)derived oligodendroglial progenitor cells (OPCs) after a $50 \mathrm{kD}$ spinal cord injury $(\mathrm{SCl})$ at $40 \times(\mathbf{A}), 200 \times(\mathbf{B}), 1000 \times(\mathbf{C})$, and $2000 \times$ (D) magnification. (A) Low magnification imaging revealed minimal pathology. (B) Higher magnification imaging of the dorsal column also revealed minimal pathology. (C) High magnification imaging revealed that structural integrity was maintained with no detectable loss of myelin sheaths or remyelination. (D) Very high magnification imaging reveals no detectable loss of myelin sheaths. Histopathology following a $200 \mathrm{kD} \mathrm{SCl}$ at $40 \times(\mathbf{E}), 200 \times(\mathbf{F}), 1000 \times(\mathbf{G})$, and $2000 \times(\mathbf{H})$ magnification.

(E) Low magnification imaging revealed widespread pathology with a region of demyelination in the dorsal column. (F) Higher magnification imaging revealed toluidine blue-stained myelin sheaths within the region of demyelination within the dorsal column, suggestive of remyelination. (G) High magnification imaging reveals extensive oligodendrocyte remyelination, as evidenced by the thin myelin sheaths relative to the axon diameter. $\mathbf{( H )}$ Very high magnification imaging reveals extensive remyelination. demonstrate that inflammation results in subse quent remyelination in areas of chronic demyelination. Thus, an increased inflammatory response in $200 \mathrm{kD}$ injures as compared with $50 \mathrm{kD}$ injures may have contributed to the superior migration in that experimental group.

The presence of endogenous O PC s may also contribute to the limited migration of transplanted cells in the $50 \mathrm{kD}$ group. Indeed, it has been shown that transplanted O PCs fail to populate normal tissue in adult animals, but will populate O PC -depleted tissue [61-63]. Although all animals in our $50 \mathrm{kD}$ injury group contained surviving cells, in all cases those cells were restricted to within $1 \mathrm{~mm}$ of the site of injection. As has been previously shown by Foote and Blakemore [63], injection of OPCs into tissue containing endogenous OPCS results in restricted migration. Due to the minimal pathology following a $50 \mathrm{kD}$ contusive $\mathrm{SCl}$, it is plausible that the transplanted cells were restricted to the site of injection due to the presence of endogenous O PCs, oligodendrocytes, or other cells.

Although transplantation of hESC-derived OPCs has been shown to improve locomotor function [33], it remained a possibility that the transplant volume or the cells themselves may have had deleterious effects that may have been masked by the severity of the $\mathrm{SCl}$, or the subsequent benefit conferred by the transplant. $\mathrm{O}$ ur data indicate that transplantation of hESC-derived O PC sinto a minor SCI is not associated with histopathology or a decline in locomotor function.

\section{Conclusion}

This study demonstrates that transplantation of hESC -derived O PC s is a safe procedure. We propose that the lack of significant pathology induced by a $50 \mathrm{kD} \mathrm{SCI}$ resulted in the absence of remyelination and limited migration by transplanted cells. $O$ ur data support the use of hESC derived OPC transplantation as a therapeutic strategy for human $\mathrm{SCI}$.

\section{Acknowledgements}

We thank Charlie M endoza and Julio Espinosa for assisance with animal care. This project was supported by Geron Corporation, the UC Discovery G rant, the Roman Reed Spinal Cord Injury Research Fund of California, Research for $\mathrm{C}$ ure, and individual donations to the Reeve Irvine Research Center. Frank Cloutier holds a post-doctoral fellowship grant from Spinal Research Foundation and The Ron Shapiro Charitable Foundation. Monica Siegenthaler holds a predoctoral NIH training grant (\#AG00096-22). 
Bibliography

1. Schucht P, Raineteau O, Schwab M E, Fouad $\mathrm{K}$ : Anatomical correlates of locomotor recovery following dorsal and ventral lesions of the rat spinal cord. Exp. N eurol. 176(1), 143-153 (2002).

2. Beattie M S, Bresnahan JC, Komon J et al.: Endogenous repair after spinal cord contusion injuries in the rat. Exp. N eurol. 148(2), 453-463 (1997).

3. Schwab M D, Bartholdi D: D egeneration and regeneration of axons in the lesioned spinal cord. Physiol. Rev. 76(2), 319-370 (1996).

4. H ayes KC, Kakulas BA: N europathology of human spinal cord injury sustained in sports-related activities. J. N eurotrauma 14(4), 235-248 (1997).

5. Bresnahan JC, King JS, M artin GF, Yashon $D$ : A neuroanatomical analysis of spinal cord injury in the rhesus monkey (M acaca mulatta). J. Neurol. Sci. 28(4), 521-542 (1976).

6. Blight AR: D elayed demyelination and macrophage invasion: a candidate for secondary cell damage in spinal cord injury. Cent. N erv. Syst. Trauma 2(4), 299-315 (1985).

7. Blight AR, Young W: Central axons in injured cat spinal cord recover electrophysiological function following remyelination by Schwann cells. J. N eurol. Sci. 91(1-2), 15-34 (1989).

8. Blight AR: M acrophages and inflammatory damage in spinal cord injury. J.

N eurotrauma 9(Suppl 1), S83-S91 (1992).

9. Blight AR: Remyelination, revascularization, and recovery of function in experimental spinal cord injury. Adv. N eurol. 59, 91-104 (1993).

10. Jeffery N D, Blakemore W F: Locomotor deficits induced by experimental spinal cord demyelination are abolished by spontaneous remyelination. Brain 120 (Pt 1), 27-37 (1997).

11. Totoiu M O, Keirstead H S: Spinal cord injury is accompanied by chronic progressive demyelination. J. Comp. N eurol. 486(4), 373-383 (2005).

12. $\mathrm{Li} \mathrm{GL}$, Brodin $\mathrm{G}$, Farooque $M$ et al.: Apoptosis and expression of $\mathrm{BCl}-2$ after compression trauma to rat spinal cord. J. N europathol. Exp. N eurol. 55(3), 280-289 (1996).

13. Crowe M J, Bresnahan JC, Shuman SL, M asters JN , Beattie M S: Apoptosis and delayed degeneration after spinal cord injury in rats and monkeys. $\mathrm{N}$ at. M ed. 3(1), 73-76 (1997).
14. Abe Y, Yamamoto T, Sugiyama $Y$ et al.: Apoptotic cells associated with Wallerian degeneration after experimental spinal cord injury: a possible mechanism of oligodendroglial death. J. N eurotrauma 16(10), 945-952 (1999).

15. Li GL, Farooque M, H oltz A, O Isson Y: Apoptosis of oligodendrocytes occurs for long distances away from the primary injury after compression trauma to rat spinal cord. Acta N europathol. 98(5), 473-480 (1999).

16. Beattie M S, Farooqui AA, Bresnahan JC: Review of current evidence for apoptosis after spinal cord injury. J. N eurotrauma 17(10), 915-925 (2000).

17. Waxman SG : D emyelination in spinal cord injury. J. N eurol. Sci. 91(1-2), 1-14 (1989).

18. Gledhill RF, B.M . H arrison, and W.I $M C D$ onald: $D$ emyelination and remyelination after acute spinal cord compression. Exp. N eurol. 38(3), 472-87 (1973).

19. Salgado-C eballos H, Guizar-Sahagun $\mathrm{G}$, Feria-Velasco A et al.: Spontaneous longterm remyelination after traumatic spinal cord injury in rats. Brain Res. 782(1-2), 126-135 (1998).

20. Bunge RP, Puckett $W R$, Becerra $J$, $M$ arcillo $A, Q$ uencer RM : O bservations on the pathology of human spinal cord injury. A review and classification of 22 new cases with details from a case of chronic cord compression with extensive focal demyelination. Adv. N eurol. 59, 75-89 (1993).

21. Kakulas BA, The applied neuropathology of human spinal cord injury. Spinal Cord. 37(2), 79-88 (1999)

22. Buss $A$, Pech $K$, M erkler $D$ et al.: Sequential loss of myelin proteins during Wallerian degeneration in the human spinal cord. Brain 128(Pt 2), 356-364 (2005).

23. Guest JD, H iester ED, Bunge RP: D emyelination and Schwann cell responses adjacent to injury epicenter cavities following chronic human spinal cord injury. Exp. N eurol. 192(2), 384-393 (2005).

24. Blakemore WF, Crang AJ: Extensive oligodendrocyte remyelination following injection of cultured central nervous system cells into demyelinating lesions in adult central nervous system. D ev. N eurosci. 10(1), 1-11 (1988).

25. Blakemore W F, Crang AJ: The relationship between type-1 astrocytes, Schwann cells and oligodendrocytes following transplantation of glial cell cultures into demyelinating lesions in the adult rat spinal cord. J. N eurocytol. 18(4), 519-528 (1989).
26. Groves AK, Barnett SC, Franklin RJ et al.: Repair of demyelinated lesions by transplantation of purified 0-2A progenitor cells. N ature 362(6419), 453-455 (1993).

27. Friedman $E, N$ ilaver $G, C$ armel $P$, Perlow $M$, Spatz L, Latov $N$ : M yelination by transplanted fetal and neonatal oligodendrocytesin a dysmyelinating mutant. Brain Res. 378(1), 142-146 (1986).

28. Kohsaka S, Yoshida K, Inoue Y et al.: Transplantation of bulk-separated oligodendrocytes into the brains of shiverer mutant mice: immunohistochemical and electron microscopic studies on the myelination. Brain Res 372(1), 137-142 (1986).

29. Duncan ID , H ammang JP, Jackson KF, Wood PM , Bunge RP, Langford L: Transplantation of oligodendrocytes and Schwann cells into the spinal cord of the myelin-deficient rat. J. Neurocytol. 17(3), 351-360 (1988).

30. Gumpel M, Gout O, Lubetzki C, Gansmuller A, Baumann N : M yelination and remyelination in the central nervous system by transplanted oligodendrocytes using the shiverer model. Discussion on the remyelinating cell population in adult mammals. D ev. N eurosci. 11(2), 132-139 (1989).

31. Rosenbluth J, H asegawa M, Shirasaki $N$, Rosen CL, Liu Z: M yelin formation following transplantation of normal fetal glia into myelin-deficient rat spinal cord. J. N eurocytol. 19(5), 718-730 (1990).

32. N istor GI, Totoiu M O , H aque N , Carpenter M K, Keirstead H S: H uman embryonic stem cells differentiate into oligodendrocytes in high purity and myelinate after spinal cord transplantation. Glia 49(3), 385-396 (2005).

33. Keirstead H S, N istor G, Bernal $\mathrm{G}$ et al.: Remyelination and locomotor recovery follows transplantation of human embryonic stem cell-derived oligodendrocyteprogenitors into acute but not chronic spinal cord injuries. J. N eurosci. 25(19): 4694-4705 (2005).

34. Xu, C, Inokuma M S, D enham J et al.: Feeder-free growth of undifferentiated human embryonic stem cells. N at. Biotechnol. 19(10): $971-974$ (2001).

35. Carpenter M K, Inokuma M S, D enham J, M ujtaba T, Chiu CP, Rao M S: Enrichment of neurons and neural precursors from human embryonic stem cells. Exp. N eurol. 172(2), 383-397 (2001).

36. Basso D M, Beattie M S, Bresnahan JC: A sensitive and reliable locomotor rating scale for open field testing in rats. J. N eurotrauma 12(1), 1-21 (1995). 


\section{hESC-derived oligodendrocyte progenitors transplanted in SCI - RESEARCH ARTICLE}

37. Barres BA, H art IK, C oles H S et al.: C ell death and control of cell survival in the oligodendrocyte lineage. Cell 70(1), 31-46 (1992).

38. Barres, BA, Raff M C: Control of oligodendrocyte number in the developing rat optic nerve. N euron 12(5), 935-942 (1994).

39. Raff M C: Size control: the regulation of cell numbers in animal development. Cell 86(2), 173-175 (1996).

40. Raff M C, Barres BA, Burne JF, Coles HS, Ishizaki Y, Jacobson M D : Programmed cell death and the control of cell survival: lessons from the nervous system. Science 262(5134), 695-700 (1993).

41. Trapp BD , N ishiyama A, Cheng D , M acklin $W$ : Differentiation and death of premyelinating oligodendrocytes in developing rodent brain. J. Cell Biol. 137(2), 459-468 (1997).

42. D avid S, M iller RH, Patel R, Raff M C: Effects of neonatal transection on glial cell development in the rat optic nerve: evidence that the oligodendrocyte-type 2 astrocyte cell lineage depends on axons for its survival. J. N eurocytol. 13(6), 961-974 (1984).

43. BurneJF, StapleJK, Raff M C: G lial cells are increased proportionally in transgenic optic nerves with increased numbers of axons. J. N eurosci. 16(6), 2064-2073 (1996).

44. Raff M C, D urand B, Gao FB: C ell number control and timing in animal development: the oligodendrocyte cell lineage. Int. J. D ev. Biol. 42(3), 263-267 (1998).

45. Casaccia-Bonnefil P: C ell death in the oligodendrocyte lineage: a molecular perspective of life/death decisions in development and disease. Glia 29(2), 124-135 (2000).

46. $M$ CM orris FA, D ubois-D alcq $M$ : Insulinlike growth factor I promotes cell proliferation and oligodendroglial commitment in rat glial progenitor cells developing in vitro. J. N eurosci. Res. 21(2-4), 199-209 (1988).
47. M ozell RL, M CM orris FA: Insulin-like growth factor I stimulates oligodendrocyte development and myelination in rat brain aggregate cultures. J. N eurosci. Res. 30(2), 382-390 (1991).

48. Barres BA, Jacobson M D, Schmid R, Sendtner M, Raff M C: D oes oligodendrocyte survival depend on axons? Curr. Biol. 3(8), 489-497 (1993).

49. Althaus H H, Kloppner S, Schmidt-Schultz $T$, Schwartz P: N erve growth factor induces proliferation and enhances fiber regeneration in oligodendrocytes isolated from adult pig brain. N eurosci. Lett. 135(2), 219-223 (1992).

50. Cohen RI, M armur R, N orton W T, M ehler $M F$, Kessler JA: N erve growth factor and neurotrophin-3 differentially regulate the proliferation and survival of developing rat brain oligodendrocytes. J. N eurosci. 16(20), 6433-6442 (1996).

51. Bertollini $L, C i o t t i ~ M T, C$ herubini $E$, Cattaneo A: N eurotrophin-3 promotes the survival of oligodendrocyte precursors in embryonic hippocampal cultures under chemically defined conditions. Brain Res 746(1-2), 19-24 (1997).

52. Kumar S, Kahn M A, Dinh L, de Vellis ): N T-3-mediated TrkC receptor activation promotes proliferation and cell survival of rodent progenitor oligodendrocyte cells in vitro and in vivo. J. Neurosci. Res. 54(6), 754-765 (1998).

53. Canoll PD, M usacchio JM, H ardy $R$, Reynolds R, M archionni M A, Salzer JL: GGF/neuregulin is a neuronal signal that promotes the proliferation and survival and inhibits the differentiation of oligodendrocyte progenitors. N euron 17(2), 229-243 (1996).

54. Louis JC, M agal E, Takayama S, Varon S: CNTF protection of oligodendrocytes against natural and tumor necrosis factorinduced death. Science 259(5095), 689-692 (1993).

55. M ayer M, Bhakoo K, N oble M : Ciliary neurotrophic factor and leukemia inhibitory factor promote the generation, maturation and survival of oligodendrocytes in vitro. Development 120(1), 143-153 (1994).
56. Dell'Albani P, Kahn M A, Cole R, Condorelli DF, Giuffrida-Stella AM, de Vellis): O ligodendroglial survival factors, PD GF-AA and CNTF, activate similar JAK/STAT signaling pathways. J. N eurosci. Res. 54(2), 191-205 (1998).

57. Komoly S, Hudson LD, Webster HD, Bondy CA: Insulin-like growth factor I gene expression is induced in astrocytes during experimental demyelination. Proc. $\mathrm{N}$ atl Acad. Sci. U S A 89(5), 1894-1898 (1992).

58. Redwine JM, Armstrong RC: In vivo proliferation of oligodendrocyte progenitors expressing PD G F $\alpha$ R during early remyelination. J. N eurobiol. 37(3), 413-428 (1998).

59. Hinks GL, Franklin RJ: Distinctive patterns of PD GF-A, FGF-2, IGF-I, and TGF- $\beta 1$ gene expression during remyelination of experimentally-induced spinal cord demyelination. M ol. Cell N eurosci. 14(2), 153-168 (1999).

60. Tourbah A, Linnington C, Bachelin C et al.: Inflammation promotes survival and migration of the $C G 4$ oligodendrocyte progenitors transplanted in the spinal cord of both inflammatory and demyelinated EAE rats. J. N eurosci. Res. 50(5), 853-861 (1997).

61. Franklin RJ, Bayley SA, Blakemore WF: Transplanted CG 4 cells (an oligodendrocyte progenitor cell line) survive, migrate, and contribute to repair of areas of demyelination in X-irradiated and damaged spinal cord but not in normal spinal cord. Exp. N eurol. 137(2), 263-276 (1996).

62. O 'Leary M T, Blakemore W F: O ligodendrocyte precursors survive poorly and do not migrate following transplantation into the normal adult central nervous system. J. N eurosci. Res 48(2), 159-167 (1997).

63. Foote AK, Blakemore W F: Inflammation stimulates remyelination in areas of chronic demyelination. Brain 128(Pt 3), 528-39 (2005). 